Chapman University

Chapman University Digital Commons

Sociology Faculty Articles and Research

Sociology

12-19-2018

\title{
Child Obesity and the Interaction of Family and Neighborhood Socioeconomic Context
}

\author{
Ashley W. Kranjac \\ Justin T. Denney \\ Washington State University \\ Rachel T. Kimbro \\ Rice University \\ Brady S. Moffett \\ Baylor College of Medicine \\ Keila N. Lopez \\ Baylor College of Medicine
}

Chapman University, kranjac@chapman.edu

Follow this and additional works at: https://digitalcommons.chapman.edu/sociology_articles

Part of the Community-Based Research Commons, Community Health and Preventive Medicine Commons, Demography, Population, and Ecology Commons, Family, Life Course, and Society Commons, $\underline{\text { Health Services Research Commons, Inequality and Stratification Commons, Maternal }}$ and Child Health Commons, Medicine and Health Commons, Other Sociology Commons, Place and Environment Commons, and the Regional Sociology Commons

\section{Recommended Citation}

Kranjac, A.W., Denney, J.T., Kimbro, R.T. et al. (2018). Child obesity and the interaction of family and neighborhood socioeconomic context. Popul Res Policy Rev, 1-23.. doi: 10.1007/s11113-018-9504-2

This Article is brought to you for free and open access by the Sociology at Chapman University Digital Commons. It has been accepted for inclusion in Sociology Faculty Articles and Research by an authorized administrator of Chapman University Digital Commons. For more information, please 


\section{Child Obesity and the Interaction of Family and Neighborhood Socioeconomic Context}

\section{Comments}

This is a pre-copy-editing, author-produced PDF of an article accepted for publication in Population Research and Policy Review, volume, issue, in year following peer review. The final publication is available at Springer via DOI: $10.1007 / \mathrm{s} 11113-018-9504-2$.

\section{Copyright}

Springer 
Title: Child Obesity and the Interaction of Family and Neighborhood Socioeconomic Context

Key Words: Neighborhoods, Child Obesity, Multi-level Modeling, Socioeconomic Status; Electronic Medical Records; Latent Profile Analysis

Word Count: 8,494 (including references)

Tables: $3+1$ Online Resource

Figures: 3 


\begin{abstract}
The literature on neighborhoods and child obesity links contextual conditions to risk, assuming that if place matters, it matters in a similar way for everyone in those places. We explore the extent to which distinctive neighborhood types give rise to social patterning that produces variation in the odds of child obesity. We leverage geocoded electronic medical records for a diverse sample of over 135,000 children aged 2 to 12 and latent profile modeling to characterize places into distinctive neighborhood contexts. Multilevel models with cross-level interactions between neighborhood type and family socioeconomic standing (SES) reveal that children with different SES, but living in the same neighborhoods, have different odds of obesity. Specifically, we find lower-SES children benefit, but to a lesser degree, from neighborhood advantages and higher-SES children are negatively influenced, to a larger degree, by neighborhood disadvantages. The resulting narrowing of the gap in obesity by neighborhood disadvantage helps clarify how place matters for children's odds of obesity and suggests that efforts to improve access to community advantages as well as efforts to address community disadvantages are important to curbing obesity and improving the health of all children.
\end{abstract}

Key Words: Neighborhoods; Child Obesity; Multilevel Modeling; Socioeconomic Status; Electronic Medical Records; Latent Profile Analysis 


\section{Child Obesity and the Interaction of Family and Neighborhood Socioeconomic Context}

\section{INTRODUCTION}

In response to dramatic increases in child obesity, a growing body of literature considers the consequences of this epidemic for children, families, and communities (Wang et al. 2011; Roberto et al. 2015). These efforts highlight the impact of obesity, especially experienced early in life, on both the trajectories of individuals and the future health and vitality of society. Although the root cause of weight gain trends in children remains elusive, a wealth of data indicate that obesogenic environments lead to changes in consumption practices and lifestyle behaviors (Swinburn et al. 2011) that drive the prevalence and severity of obesity in children. While this literature increases our understanding of the demographic and socioeconomic variation in child obesity, we know little about how multiple demographic factors may combine to produce steep socioeconomic gradients in obesity among children living in a single residential context and still less about the role neighborhood socioeconomic status (SES) plays in these disparities.

Scholars are increasingly attending to the relationship between self and place to better understand socioeconomic impact on obesity outcomes (Ludwig et al. 2011; Alvarado 2016). In fact, many recent studies link child demographic data to measures of area deprivation to draw out the impact of neighborhood factors on children's weight status above and beyond individual and family-level characteristics (Kimbro and Denney 2013; Carroll-Scott et al. 2013; Grow et al. 2010). It has been shown, for example, that neighborhoods with higher concentrations of poverty have increased child obesity prevalence (Grow et al. 2010; Kimbro and Denney 2013). This indicates that children 
who are at higher risk for a multitude of health and developmental problems are also living in places that exacerbate those risks. It is also likely, however, that the influence is multi-directional and may also flow from the family context to the neighborhood environment (Arcaya et al. 2016). The research on neighborhoods and child well-being has largely linked specific neighborhood conditions (e.g., the built environment) to child obesity in order to generate an average effect of the neighborhood environment on child obesity. This prior work thus implicitly assumes that if place matters, it matters in a similar way for everyone in those places (e.g., access to healthy foods influencing all community members). A clear connection between the empirical evaluation of how neighborhoods matter differently by child characteristics and a theoretical premise for why the residential context is experienced differently by specific segments of the population is needed (Sharkey and Faber 2014) to advance the literature on neighborhoods and child obesity.

In the present analysis, we investigate whether children with different family SES, but living in the same neighborhood contexts, have differing odds of obesity. We systematically explore the extent to which distinctive residential environments give rise to social patterning that produces variation in obesity prevalence. We examine the complexities of associations between child obesity, area disadvantage, and neighborhood-level social characteristics through a more nuanced lens by leveraging unique electronic medical record data and using latent profile modeling techniques to characterize neighborhoods into areas of distinctive physical and social contexts. We then use a series of models to examine how the residential socioeconomic context impacts children differently by household SES. 


\section{BACKGROUND}

\section{Socioeconomic differences in child obesity}

Sociologists have long considered disparities in health as evidence of the systemic socioeconomic patterning of stratification that is evident in American neighborhoods (Sampson 2008). Indeed, considerable research describes the socioeconomic disparities in child obesity and a stream of work focuses on how neighborhood conditions might influence these disparities. Explanations for why neighborhood factors might influence child obesity, specifically, include differences in institutional resources such as schools, parks, and healthy food options, as well as the socioeconomic composition of the neighborhood (Jencks and Mayer 1990; Shonkoff and Phillips 2000). Other lines of work highlight that the effects of neighborhoods may reach far beyond the physical characteristics of the community (Sampson and Sharkey 2008; Arcaya et al. 2016). Brooks-Gunn and colleagues (1993), for example, first show that living in areas characterized by high rates of crime and deprivation may lead to worse developmental outcomes in children through mechanisms related to stress and adaptation.

Much of this work incorporates a range of socioeconomic and social cohesion indicators to differentiate neighborhood conditions, including measures of concentrated disadvantage (Kimbro and Denney 2013), parent-reported neighborhood resources and safety (Singh, Siahpush, and Kogan 2010), crime rates (Carroll-Scott et al. 2013), lower mean levels of education, median household income, and home ownership (Grow et al. 2010). Across all of these studies, neighborhood factors representing lower SES and greater social disorder are shown to be significant predictors of child obesity, beyond 
individual-level factors. A wealth of literature also quantifies the growing disparities in obesity outcomes in an attempt to disentangle the relative prominence of social and contextual associations that contribute to these disparities (see Wang and Beydoun 2007 for a review). Thus, it seems clear that indicators representing lower SES and social disorder at the neighborhood level are associated with increased prevalence of child obesity. These studies, however, all estimate average effects across all neighborhoods. It is unclear whether some children's obesity status might be more resilient - or more vulnerable - to neighborhood conditions due to neighborhood effect heterogeneity.

\section{Neighborhood effect heterogeneity on child obesity}

It is likely that the same context is not universally experienced across groups or individuals, and this differential in experience can be reflected in neighborhood effect heterogeneity (Harding et al. 2010). Children living in the same residential context may have different levels of exposure to neighborhood conditions that construct their experience of the community in which they live and, in turn, may differentially shape the impact of community characteristics on individual well-being (Harding et al. 2010; Sharkey and Faber 2014). The most convincing evidence of this emerges from the Moving to Opportunity (MTO) project. Kling and colleagues (2005), for example, find that girls, relative to boys, receive greater gains in school performance and mental health after moving to a less impoverished community. This finding is further supported by ethnographic work conducted at the MTO sites showing that peer influences, friendship networks, and use of space also vary by gender (Clampet-Lundquist et al. 2011). As Sharkey (2006) contends, to some extent, exposure levels to different 
neighborhood characteristics are governed by children (and their parents) through decisions, likely conditioned by family SES (Sampson 2002), about where, how, and with whom to spend time. Interaction with other neighborhood children (Crowder and South 2003), access to community resources (Allard and Small 2013), and involvement in the community (Sharkey 2010), all drive neighborhood effects and vary by child and his/ her family (Sharkey 2006).

This substantial variation in children's experiences of the same residential context may exist due to the variant patterns of interaction between child and family characteristics and neighborhood conditions (Harding et al. 2010). For example, girls and adolescents experience higher odds of obesity relative to boys and younger children due to neighborhood disadvantage (Alvarado 2016). Moreover, developmental and behavioral problems comorbid with child obesity (Halfon et al. 2013) link to children's low SES and neighborhood disadvantage (Singh \& Ghandour 2012). In addition, parents may use avoidance management strategies in response to neighborhood violence and require that children remain indoors after school (Harding et al. 2010), likely engaging in sedentary behaviors, or permit play outside only under strict parental supervision. The impact of these two reactions to the same neighborhood circumstance for obesity is harmful in the first case when children are relegated indoors and beneficial in the second when parents allow children to engage in play under their supervision, and thus could generate variation for different children living in the same community. 


\section{Hypotheses}

We motivate our hypotheses by focusing on the incongruence of children's sociodemographic characteristics within distinctive neighborhood contexts. We begin by hypothesizing that, in general, the more disadvantaged the community the higher the odds of obesity for children in those communities. This is derived from prior research (Grow et al. 2010; Kimbro and Denney 2013). Thus,

$\mathrm{H} 1$. The odds of obesity for children will be higher in more socioeconomically disadvantaged communities than in less disadvantaged communities.

Next, we consider whether the influence of a disadvantaged neighborhood differs across children in more and less advantaged families. We develop two additional hypotheses that focus on the relative impact of neighborhood context on child obesity by family SES.

It may be that neighborhood disadvantages accumulate along with family disadvantages (Ferraro \& Kelley-Moore 2003). In this scenario, and in line with the cumulative disadvantage perspective, children's low family SES may fail to buffer against the additional deleterious effects of living in a disadvantaged community. In contrast, higher-SES children may be less influenced by neighborhood conditions and thus maintain relatively healthy weights by leveraging their family advantages to avoid obesogenic neighborhood factors. As a consequence, the gap in obesity between lowand high-SES children grows as neighborhood disadvantage increases.

Alternatively, pursuant to the Blaxter hypothesis, increasing neighborhood disadvantage might influence high-SES children more than low-SES children (Blaxter 1990). If more socioeconomically advantaged children live in areas characterized by features of socioeconomic and other disadvantages, those children may be exposed to 
a more obesogenic environment (Townshend and Lake 2009) and adhere more closely to local weight-related behaviors and expectations. Meanwhile, children from low-SES families are more accustomed to the health norms and customs of lower-SES neighborhoods. In this way, the impact of the neighborhood environment might be enhanced for higher-SES children, and socioeconomic advantages typically leveraged toward better health may not be realized to the same extent when living in a less advantaged place. This heterogeneity between family SES and neighborhood conditions will in turn impact the odds of obesity differently and ultimately shrink the gap in obesity between lower-SES and higher-SES children the more disadvantaged the neighborhood. Thus, we test the following two competing hypotheses:

$\mathrm{H} 2 \mathrm{a}$. Increasing neighborhood disadvantage will impact the odds of obesity more for low-SES children than for high-SES children, resulting in a larger gap in obesity the more disadvantaged the neighborhood.

$\mathrm{H} 2 \mathrm{~b}$. Increasing neighborhood disadvantage will impact the odds of obesity more for high-SES children than for low-SES children, resulting in a smaller gap in obesity the more disadvantaged the neighborhood.

\section{METHODS}

\section{Data Sources}

Our focal data set is a compilation of electronic medical and administrative records from the largest single system network of pediatric clinics and hospital admissions in the country in Houston, TX. Medical records include inpatient and emergency room pediatric encounters at a large pediatric hospital as well as outpatient visits to one of 50 pediatric clinics throughout the Houston metropolitan area for all patients who were $2-12$ years old between 2011 and 2013. To be included in our analysis, children needed at least one outpatient record. Children who only had 
inpatient records were not included because BMI is less frequently tracked for inpatient visits. We randomly selected one child per family to eliminate bias at the household level.

The pediatric electronic medical records were geocoded to the Census tract level and then linked to neighborhood-level social, economic, walkability, and crime data to provide a comprehensive portrait of the different kinds of neighborhoods in Houston, TX. We follow prior work and use census tracts to represent neighborhoods (Massey et al. 1994). Although census tracts are by no means a perfect operationalization of neighborhoods (Tienda 1991), they remain a useful spatial entity available to us in the approximation of a neighborhood (Arcaya et al. 2016; White 1987). Social and economic indicators were generated using the 2010 decennial Census files and 2009 -

2013 American Community Survey (ACS) data. Walkability was determined using 2011 - 2013 data from WalkScore.com. Crime data were derived from 2011 - 2013 monthly Uniform Crime Reports (UCR) provided by the City of Houston police department. Crime statistics, by offense type and frequency, were aggregated to the tract-level from police reports by district and beat.

\section{Measures}

The key outcome measure is a dichotomous variable indicating whether or not the child is obese. Because these are clinical records, height and weight are objectively measured at time of medical visit. This provides an advantage over parent-reported survey data, which may be prone to bias (Dubois and Girad 2007). We selected each child's first visit between 2011 and 2013, and used measures from that visit. We calculated body mass index (BMI) from height and weight measures using the standard 
formula (weight $[\mathrm{kg}] /$ height $[\mathrm{m}]^{2}$ ). Children were coded as being obese if they had an age- and sex-specific BMI $\geq 95^{\text {th }}$ percentile (Wang and Chen 2012). Obesity rates in our data are comparable to other local and state estimates, giving us confidence in the results reported here (RWJF 2017).

We include all available covariates from the medical record to represent child and familial characteristics. Child characteristics include age at recorded time period, gender, race/ethnicity, and child's insurance type as a proxy for SES. Age is a continuous measure and represents the age of the child when he/she visited the clinic, centered on the mean age of children in our sample ( 5.70 years, $S D=3.22)$ for ease of interpretation. Gender is a dichotomous variable and represents whether or not the child is male, with female as the referent. Race/ethnicity is a categorical measure representing the parent-reported race/ethnicity of the child categorized as non-Hispanic White (referent), non-Hispanic Black, Hispanic, and Asian/other race. Insurance type is a categorical measure indicating the type of medical insurance held by the child at the time of the visit, and is categorized as private provider (referent) or public provider (e.g., Children's Health Insurance Program (CHIP) or Children's Medicaid). While using insurance type as a proxy for SES is far from ideal, insurance coverage is widely used as a marker for individual-level SES with reasonable validity (Goyal et al. 2011; Casey et al. 2013; Kristal et al. 2015).

Nearly $38 \%$ of children were missing on measures of either race/ethnicity or insurance type. Typically, we would impute values for children with missing data on these specific characteristics; however, multiple imputation would not be appropriate due to the lack of comprehensive individual-level measures (Allison 2001). As such, we 
used listwise deletion to eliminate children who were missing on race/ethnicity ( $n=$ $21,706)$ or insurance type $(n=49,820)$ resulting in 135,974 children for analysis. Estimates presented here are substantively similar to supplementary analyses where we estimated models on the full sample and included an indicator for whether the child was missing on race/ethnicity or insurance type (available upon request). Finally, we compared the representativeness of our electronic medical records by comparing our racial/ethnic proportions to those from the American Community Survey (ACS) in the Houston metropolitan area. For example, the ACS 5 year estimates from 2009-2013 show $58 \%$ white, $24 \%$ black, $44 \%$ Hispanic, and $6 \%$ Asian, which is closely aligned with our data presented in Table 2 .

The neighborhood data include social, economic, walkability, and crime measures known to be independently associated with obesity. Social and economic indicators were generated using the Census and ACS data and include educational attainment, unemployment rate, median income, median year the house was built, percent of female-headed households, percent foreign born, percent receiving public assistance, percent in poverty, and percent of homes that are vacant in the tract. The walkability measure extracted from Walkscore.com isolates whether, and the extent to which, a pedestrian can access key residential services such as grocery stores, schools, parks, and leisure spaces in a given area with minimal automobile use (Leinberger 2013). Higher scores indicate greater pedestrian accessibility. For crime data derived from the City of Houston police department, we followed the model by Tabarrok, Healton, and Helland (2009) and partitioned the offenses into violent (murder, rape, robbery, aggravated assault) and non-violent (burglary, theft, auto theft). We then 
calculated the proportion of violent and non-violent crime for a given tract. We control for neighborhood population density in all models. The research was conducted in accord with prevailing ethical principles and approved by the Rice University and Baylor College of Medicine Institutional Review Boards.

\section{Statistical Analyses}

We first used a maximum-likelihood latent profile analysis (LPA; Lazarsfeld and Henry 1968) to shed light on the graded relationship between children's odds of obesity and neighborhood type. We characterize neighborhoods into clusters based on a range of social, economic, and physical indicators frequently used to define a child's neighborhood of residence (Jencks and Mayer 1990). We include mean levels of educational attainment, rates of unemployment, median household income levels, median year the house was built, percent foreign born, percent of homes that are vacant in the tract, crime, and walkability. We did not include race/ethnic composition in the construction of the residential environments to reduce the amplification of direct effects with the inclusion of individual values and group level values on the same variable (i.e., endogenous effects; Manski 1993). We did, however, test the robustness of our results with the inclusion of neighborhood racial/ethnic concentration in two sets of analyses, with percent black and percent Hispanic. The substantive interpretation of the findings reported here did not change with the inclusion of these level 2 covariates (available upon request).

We estimated a 1-class model and fit successive models with an increasing number of classes to characterize neighborhoods. We used entropy and theoretically driven evidence to select the most appropriate number of profiles. We identified the 
most parsimonious model through Bayesian information criterion (BIC), p-value-based likelihood ratio tests, and bootstrap p-value. Analyses indicated that neighborhoods in the Houston metropolitan area, given our data, are most appropriately captured by a 4class solution (see Online Resource 1).

To test the impact of neighborhood conditions on the odds of obesity among children we estimated multi-level logistic regression models (Guo and Zhao 2000; Rabe-Hesketh and Skrondal 2008) with Stata 14 software (StataCorp 2015). The models treat level-1 children as nested within level-2 neighborhoods. All models use maximum likelihood estimation with adaptive quadrature (Rabe-Hesketh and Skrondal 2008). This approach adjusts for problems that otherwise downwardly bias estimated standard errors including clustering within neighborhoods, different sample sizes for level-1 and level-2 units, heteroscedastic error terms, and variable numbers of cases within level-2 units (Raudenbush and Bryk 2002). We test hypothesis 1 by including level-2 neighborhood type (and a level-2 error component $\mathrm{u}_{j}$ ) along with the level-1 predictors and an individual error term ( $\left.e_{i j}\right)$. For example, equation 1 represents the logged odds of obesity, allowing the odds to vary across neighborhoods, and includes child health insurance type $\left(\beta_{1 \mathrm{j}}\right), \mathrm{k}$ control variables, and the neighborhood type $\left(\mathrm{N}_{\mathrm{j}}\right)$ as a level-2 explanatory variable:

$\ln [\operatorname{Prob}(Y=1) / \operatorname{Prob}(Y=0)]=\beta_{0 j}+\beta_{1 j} * X_{i j}+\sum \beta_{k i j}{ }^{*} X_{k i j}+\beta_{2 j} * N_{j}+u_{j}+e_{i j}$

To test hypotheses $2 \mathrm{a}$ and $2 \mathrm{~b}$ we included cross-level interactions (Meyers 2006) between neighborhood type and child insurance type (Table 3, Model 3; equation not shown). These models treat the intercept $\left(\beta_{0 \mathrm{j}}\right)$ and the child insurance effect $\left(\beta_{1 \mathrm{j}}\right)$ as random across neighborhood types and the effects of the control variables as fixed. We 
report coefficients and odds ratios (OR) from the regressions. To ease interpretation of the cross-level interactions, we produce fully adjusted predicted probabilities from the regression estimates for obesity by child insurance type across the different types of residential contexts.

\section{RESULTS}

Figure 1 depicts how the 4 neighborhood profiles cluster in the Houston metropolitan area. Based on the descriptive characteristics and location of these neighborhood types, we assigned descriptive labels of Urban Elites (i.e. high SES and low crime), Suburban Elites, Suburban Strivers, and Urban Strivers (i.e. low SES and high crime). The most advantaged neighborhoods, Urban Elites, cluster in the south and west parts of the city center. As shown in Table 1, Urban Elites have the highest median household income $(\$ 124,000)$, highest overall levels of education (63\% of residents had at least 16 years of education), lowest percentage of people living in poverty (4\%), lowest proportion of violent crime (5\% violent), and are the most walkable (46.72 average walk score out of 100). In comparison, Urban Strivers make up the north, east, and southern parts of the central city, and are the most disadvantaged neighborhoods on nearly every indicator. They have the lowest median household income $(\$ 35,100)$, the lowest education levels ( $43 \%$ of adult residents lack a high school degree), the highest proportion of the population in poverty (44\%), and the highest proportion of violent crime (20\%).

$<$ Table 1 and Figure 1 about here>

Table 2 displays means and standard errors for child and family characteristics overall and by residential context. Obesity prevalence is significantly different across 
neighborhoods. For example, children living in Urban Strivers have higher rates of obesity (13\%) than children living in Suburban Strivers (10\%), Suburban Elites (6\%), and Urban Elites (4\%). The racial/ ethnic and socioeconomic measures show considerable child- and family-level variation across residential environments. The majority of children in the most affluent areas are Non-Hispanic Whites with private insurance (Urban Elites: 68\% Non-Hispanic White, 94\% privately insured; Suburban Elites: $62 \%$ Non-Hispanic White, $85 \%$ privately insured). Suburban Strivers have similar percentages of Non-Hispanic White (34\%), Non-Hispanic Black (29\%), and Hispanic (35\%) children, with $56 \%$ of children privately insured. The most disadvantaged communities, Urban Strivers, have, on average, 11\% Non-Hispanic White, 20\% NonHispanic Black, and $67 \%$ Hispanic children, and $30 \%$ of children in Urban Strivers are privately insured. Even though there are stark differences in the racial and ethnic representation in the four neighborhood types, as well as large differences in insurance coverage, there remain large numbers of children with different demographic characteristics in each of the neighborhood types. This is illustrated in Figure 2, which depicts the distribution of publically and privately insured children across neighborhood types. In other words, there is sufficient variation in neighborhood exposures for children of all race/ethnicities and socioeconomic levels in our data to assess whether the impact of neighborhood environment differs across children.

$<$ Table 2 and Figure 2 about here $>$

Table 3 presents results of our multilevel logistic regression models predicting child obesity. Model 1 includes age at recorded time period, gender, race/ethnicity, and insurance type at level-1 and population density (logged) at level-2. Model 2 adds 
neighborhood type at level-2, and Model 3 adds a cross-level interaction between the neighborhood type and insurance type (our proxy for SES) of child. In Model 1, we see that older children, Non-Hispanic black and Hispanic children, and publicly-insured children have higher odds of obesity. Asian/other children, relative to white children, have lower odds of obesity; and boys are as likely to be obese as girls. In Model 2, accounting for neighborhood type slightly reduces the race/ethnic and insurance type differences in the odds of obesity, indicating that some of the higher odds of obesity for Non-Hispanic blacks and Hispanics relative to whites, and publicly-insured children relative to privately-insured children, is due to neighborhood context. Turning next to the odds ratios for the neighborhood categories, we see that there is a graded relationship between neighborhood disadvantage and child obesity. Children living in the most disadvantaged neighborhoods, the Urban Strivers, have more than two and a half times the odds of obesity relative to children living in the most advantaged neighborhoods, the Urban Elites. Accounting for child's age, gender, race/ ethnicity, and insurance type, the more disadvantaged the community in which a child lives, the higher the odds of obesity.

$<$ Table 3 about here $>$

Next, we examine whether distinctive residential contexts influence the odds of obesity differently based on family SES, measured by insurance type.

In Model 3, when we add our cross-level interaction between neighborhood and insurance type, we see that the impact of all neighborhood types on obesity odds differs by child insurance type, such that publicly insured children's odds of obesity are less impacted by living in a disadvantaged neighborhood relative to privately insured 
children. Thus, children with public insurance have 2.2 times the odds of clinically assessed obesity compared to private insurance holders living in the same advantaged (or Urban Elites) community. However, as neighborhood disadvantage increases, moving from top to bottom of Model 3 in Table 3, the interaction coefficients are consistently negative and significant, indicating that the slope for publicly insured children, relative to privately insured children, is less steep. Finally, information at the bottom of Model 3 in Table 3 indicates that the random slope for insurance type is, in fact, significantly different by residential context.

Figure 3 uses the information generated from Model 3 in Table 3 and provides fully adjusted predicted probabilities of obesity for public and private insured children across the neighborhood types. The figure illustrates two important trends in the probability of obesity among children. First, the gap in obesity for children by family SES is largest in the most advantaged neighborhoods. For example, the likelihood of obesity for children with public insurance in Urban Elites (.07) is higher than the likelihood for privately insured children $(.03 ; p \leq 0.001)$. Second, the likelihood of obesity by neighborhood disadvantage rises faster for privately insured children than for publically insured children. Moving left to right of Figure 3, as neighborhood disadvantage increases, the probability of obesity for children with public insurance moves from .07 to nearly .14 in Urban Elites versus Urban Strivers neighborhoods. Children with private insurance, however, see a larger increase, from .03 in the most advantaged neighborhoods to over .12 in the most disadvantaged neighborhoods. The result is a narrowing of the gap in obesity between more and less advantaged children the more disadvantaged the neighborhood. In fact, the fully adjusted probability of obesity for 
privately and publically insured children in Suburban Strivers, the next to most disadvantaged neighborhood type, is statistically indistinguishable, 0.104 for public insurance and 0.099 for private insurance.

< Figure 3 about here >

Finally, because children who are publicly insured likely differ from children who are privately insured on many characteristics, which we cannot directly observe, Models 4 and 5 stratify the sample by insurance type. Indeed, the first finding to note is how dramatically the race/ethnic odds ratios differ across the private and publicly-insured models, due in part to the large race/ethnic differences in the composition of each sample. For example, among publicly-insured children, there is no difference in the odds of obesity between Non-Hispanic black and Non-Hispanic white children. Next, the neighborhood type odds ratios are quite different across the stratified models. For privately insured children, living in a Suburban Elites neighborhood is associated with 1.7 times higher odds compared to living in the most advantaged neighborhoods. For a privately-insured child, living in a Suburban Strivers or Urban Strivers neighborhood is associated with nearly three times higher odds of obesity compared to living in an Urban Elites neighborhood. In contrast, there is no significant difference in the odds of obesity for publicly-insured children living in Suburban Elites relative to those in Urban Elites, and the increase in odds for Strivers neighborhoods, while significant, is more modest. The table also notes that differences in the effect of neighborhood type on child obesity across the private and public-insured models are significantly different from each other. This provides more evidence that, indeed, neighborhood disadvantage is more 
impactful on increasing the obesity odds for privately insured children than for publically insured children.

\section{DISCUSSION}

We investigated whether distinctive residential contexts generate variation in the odds of obesity by SES. Aligned with previous studies, and consistent with $\mathrm{H} 1$, we show that the likelihood of obesity is higher for children in more socioeconomically disadvantaged areas. We add to this literature by examining additional hypotheses and finding that the impact of neighborhood disadvantage is different for children of different socioeconomic standing, such that higher-SES children's odds of obesity in disadvantaged communities are more impacted by the community in which they live relative to other lower-SES children living in those same neighborhoods. In part, our use of Latent Profile Analysis (LPA) provided analytical strength in the characterization of the city of Houston into different kinds of environments that children may reside. As a result, our findings indicate that when the differential experiences of children in the same neighborhood are accounted for within distinct residential environments, the gap in obesity between children by social status begins to converge.

Considerable empirical research indicates that neighborhood effect heterogeneity should be considered when isolating the impact of distinctive residential environments on child outcomes (Sampson 2008; Harding et al. 2010; Sharkey 2006, 2010; Sharkey and Faber 2014). For example, studies indicate that boys procure greater gains from living near affluent neighbors than girls in terms of IQ scores, verbal ability, and reading achievement scores (see Leventhal and Brooks-Gunn 2000, for review). Disentangling these associations, however, introduces several challenges for neighborhood 
researchers that exploit large survey or experimental data sets. For example, Sampson (2008) attempted to analyze the differential impact of exposure to highly disadvantaged groups using the MTO data, but because children from different socioeconomic backgrounds occupy entirely different types of communities in cities like Baltimore and Chicago, the examination was not possible.

Our data source, geocoded medical records from the largest single system network of pediatric clinical settings in the country located in Houston, Texas, allows us to overcome some of the methodological challenges involved in trying to uncover neighborhood effect heterogeneity. As a setting, Houston represents the demographic future of the U.S. (Lewis et al. 2011) due to its racial/ethnic compositional makeup, and although socioeconomically and racially segregated like most major urban areas, Houston's ethnic diversity and lack of zoning results in an eclectic mix of residents living near one another. We are able to take advantage of this heterogeneity along with the large number of children of all race/ethnicities and socioeconomic levels clustered within neighborhoods (see Table 2 and Figure 2) and the large sample size to estimate differential impacts of family SES by neighborhood context on children's odds of obesity.

Extant research indicates that multiple components of a child's residential environment influences his/her likelihood of being obese (Kimbro and Denney 2013; Carroll-Scott et al. 2013; Grow et al. 2010). Largely unknown, however, is the extent to which distinctive residential contexts impact obesity in different ways for different children who also live in the same neighborhood. Several known mechanisms through which a child might experience a single residential context differently based on SES 
have been identified. Most notable for the present analysis is the economic composition within a particular residential context. We focus on this aspect because of the known bundling of spatial advantages or disadvantages present within this dimension (Sharkey 2013). Every individual, familial, and contextual factor, however, works in unison to create a varied experience for each child and depending on how a child adapts to these components physiologically, psychologically, and socially his/her chance of being obese may be influenced in different ways compared to that of the child next door. These complex processes inform a multitude of dimensions that generate an infinite number of possibilities to either contribute to, or counteract, obesity.

Our results provide evidence, consistent with $\mathrm{H} 2 \mathrm{~b}$, that higher-SES children's odds of obesity are more impacted by living in a lower-SES area. Although it is beyond the scope of our analysis to examine precisely why, it may be that economically advantaged children living in communities characterized by disadvantage, such as higher rates of crime and diminished walkability, are more vulnerable to neighborhood context. In this way, and in line with work from Blaxter (1990), the impact of the neighborhood environment matters less for lower-SES children perhaps due to already high rates of exposure to the deleterious effects of social disadvantage. The direction and magnitude of these two adaptations push in opposite directions, thereby generating more pronounced differences in the odds of obesity by sociodemographic attributes. In other words, neighborhood disadvantage associates with greater weight among children overall, and it does so differentially by child and family characteristics. Given that the neighborhood environment influences children's obesity status between the ages of 212 years old, however, the magnitude of this effect is likely to increase in adolescence 
(Harding et al. 2009) and adulthood (Sokal-Gutierrez 2017) when peers and neighborhoods begin to assume an increasingly important role in influencing weightrelated behaviors and attitudes.

One mechanism through which this variation might occur is through residential social networks. Social networking paths closely follow socioeconomic lines and are a key source through which weight-related cultural scripts are transmitted to children (Muttarak 2018). Children and families within a neighborhood tend to share specific cultural and social norms (Jencks and Mayer 1990; Shonkoff and Phillips 2000) that might motivate weight-related behaviors including dietary practices and physical activity levels, all of which influence the likelihood of obesity. A similar pattern is observed when peer groups serve as the primary agent of socialization for adolescents (Umberson, Crosnoe, and Reczek 2010). Variation in the internalization of these norms and attitudes that are present within the neighborhood might serve to inhibit or increase the odds of obesity differently for children. For example, the concentration of children within a neighborhood who are obese may lead, in some spaces, to an overarching normative acceptance of obesity as collective attitudes towards it are focused more on living with it than on preventing it (Powell and Kahn 1995). In other contexts, obesity prevalence may serve to increase awareness and encourage preventative measures.

Consequently, although social referents within the neighborhood context operate in the periphery of the child's social network (Childers and Rao 1992), they still exert a degree of influence on children's weight-related behaviors.

A second source of variation in child obesity risk within residential contexts is children's different physiological, emotional, or social responses to the challenges of 
daily life in disadvantaged environments. Sharkey (2006) made the distinction between imposed environments (everything that exists in the neighborhood where a child lives) and selected environments (the people and institutions with whom he or she interacts) to emphasize that children living in the same neighborhood may choose very different milieu for themselves. It follows, then, that the choices children (and their parents) make may impact the odds of obesity differently for different children within the same context. For example, Crosnoe (2009) found that impoverished students perform worse academically when attending middle-class schools than when in schools with similar peers. He finds that this is largely due to stigmatization and diminished social recognition. Crosnoe argues that how students perform is a function of the way in which they view themselves, along with how they perceive others to evaluate them relative to their peers. If we apply this theory to differences in child obesity, it is possible that cultural authenticity within a disadvantaged neighborhood (Harding 2009) may take the form of appropriate body size, and influence obesity outcomes in children.

\section{Limitations}

To the best of our knowledge, we are the first to suggest and examine variation in obesity risk among different children living in the same residential context. However, this study is not without limitations. Electronic medical records, like most data, come with advantages and disadvantages. We have a large and diverse number of patients nested within the same neighborhoods with objectively measured indicators such as height and weight, but the patient record is primarily intended for clinical and administrative use. Accordingly, the variables available for analysis are often limited due to issues of privacy and security. Thus, the present analysis is constrained by the 
rudimentary control measures available in the electronic medical record data, therefore limiting the scope of our analysis and likely masking more nuanced patterns. For example, we do not have information on health care quality though prior research indicates that quality of care differs by insurance type (Kreider et al. 2016). We also use a public-private insurance type dichotomization as a proxy measure for SES. While it is not ideal to use insurance type as a proxy for SES, publicly provided health care coverage such as Medicaid is only available to children who meet stringent income criteria, with the exception of some that suffer from limited medical conditions (Rosenbaum 2002). In addition, insurance coverage is widely used as a marker for individual-level SES with reasonable validity and reliability (Goyal et al. 2011; Casey et al. 2013; Kristal et al. 2015). Future researchers should apply a more comprehensive set of covariates to test the reliability of our findings, and include individual- and familylevel conditions known to track with obesity (e.g., parenting behaviors, peer group influences).

Further, although only $6 \%$ of children in Urban Elites neighborhoods have public health insurance, which may impact standard errors, this lack of variation is offset by our large sample size. Also, because we treat latent class membership as a manifest categorical variable in a larger model of interest our approach of first classifying individuals into latent classes and then performing a subsequent analysis may induce attenuation in our estimates (Bray et al. 2015; Oberski 2016). Online Resource 1, however, provides evidence that our classify-analyze approach induces bias but does not have a meaningful impact on findings. To be sure, like any analytical technique LPA comes with its own suite of limitations. Still, we believe our analysis can inspire future 
research efforts into treating neighborhoods as influential for health and well-being through bundles of risks and resources. Indeed, these future efforts might incorporate other diagnostic procedures, such as the evaluation of bivariate residuals (BVR) and the comparison between the associations with latent variables and individual items (see Vermunt and Magidson 2002).

Moreover, despite that our patient sample is drawn from all 13 counties in the Houston metropolitan area, our sample is still limited to this region, reducing the generalizability of our findings to a portion of children in the Houston, TX region between the years of 2011 and 2013. In addition, the cross-sectional nature of our data is a methodological limitation that attenuates the ability to make causal inferences. Finally, we believe our analyses further call for different conceptualizations or foci in characterizing places. Where we focus on family and neighborhood social and economic conditions explicitly, other research might focus on, for example, family and child propensities to spend time outside in parks or otherwise recreating and evaluating those associations in the context of explicit neighborhood accessibility for outdoor recreation. Doing so will further our understanding of neighborhood heterogeneity and its relevance in linking place to well-being.

Despite these limitations, researchers generally lack access to data that explicitly link social determinants of health to children's obesity prevalence among specific subgroups of children in a single residential environment. The current study addresses this deficit by using more than 135,000 medical records from a diverse group of children residing in Houston, TX, linked to demographic and multifaceted contextual data. Using an innovative analytical technique to characterize neighborhood types across the city 
we show that neighborhood disadvantage matters differently for children's obesity based on their (and their parent's) socioeconomic position. Our findings allow neighborhood researchers to move beyond the simple linkages of neighborhood conditions to child obesity and demonstrate how this association varies for specific subgroups of children from distinctive residential environments. 


\section{References}

Allard S, Small ML. 2013. Reconsidering the urban disadvantaged: the role of systems, institutions, and organizations. The Annals of the American Academy of Political and Social Sciences 647(1):6-20.

Allison, P. D. 2001. Missing data (Vol. 136). Sage publications.

Alvarado, Steven Elías. 2016. Neighborhood disadvantage and obesity across childhood and adolescence: Evidence from the NLSY children and young adults cohort (1986-2010). Social Science Research 57: 80-98.

doi:10.1016/j.ssresearch.2016.01.008.

American Community Survey: Demographic and Housing Characteristics, 2011-2015, U.S. Census Bureau. https://factfinder.census.gov, Accessed October 28, 2017

Arcaya, M., Tucker-Seeley, R., Kim, R., Schnake-Mahl, A., So, M., \& Subramanian, S. 2016. Research on Neighborhood Effects on Health in the United States: A Systematic Review of Study Characteristics. Social Science \& Medicine 168: 16-29.

Arcaya, M., Graif, C., Waters, M., and S.V. Subramanian. 2016. Health selection into neighborhoods among families in the Moving to Opportunity program. American Journal of Epidemiology 183(2): 130-137.

Blaxter, Mildred. 1990. Health and Lifestyles. London: Tavistock.

Bray, Bethany C., Lanza, Stephanie T., and Xiamming Tan. 2015. "Eliminating bias in classify-analyze approaches for latent class analysis." Structural Equation Modeling 22(1): 1-11.

Brooks-Gunn, J., Duncan GJ, Klebanov, PK,Sealand, N. 1993. Do neighborhoods influence child and adolescent development. American Journal of Sociology 99(2):35395.

Carroll-Scott A, Gilstad-Hayden K, Rosenthal L, Peters SM, McCaslin C, Joyce R, et al. 2013. Disentangling neighborhood contextual associations with child body mass index, diet, and physical activity: the role of built, socioeconomic, and social environments. Social Science \& Medicine 95:106-14.

Casey, JA, Curriero, FC, Cosgrove, SE, Nachman, KE, Schwartz, BS. 2013. Highdensity livestock operations, crop field application of manure, and risk of communityassociated methicillin-resistant Staphylococcus aureus infection in Pennsylvania. JAMA Internal Medicine 173:1980-90.

Crosnoe R. 2009. Low-income students and the socioeconomic composition of public high schools. American Sociological Review 74(5):709-30. 
Crowder K, South SJ. 2003. Neighborhood distress and school dropout: the variable significance of community context. Social Science Research 32:659-98.

Dondero, Molly and Jennifer Van Hook. 2016. Generational Status, Neighborhood Context, and Mother-Child Resemblance in Dietary Quality in Mexican-origin Families. Social Science and Medicine 150: 212-220.

Dubois L, Girad M. 2007. "Accuracy of maternal reports of pre-schoolers' weights and heights as estimates of BMI values." International Journal of Epidemiology 36:132-8.

Ellen IG, Turner MA. 1997. Does neighborhood matter? Assessing recent evidence. Hous. Policy Debate 8(4):833-66.

Ellen IG, Turner MA. 2003. Do neighborhoods matter and why? In Choosing a Better Life? A Social Experiment in Leaving Poverty Behind: Evaluation of the Moving to Opportunity Program, ed. JM Goering, JD Feins, pp. 313-38. Washington, DC: Urban Inst. Press.

Ferraro, Kenneth F., and Jessica A. Kelley-Moore. 2003. Cumulative Disadvantage and Health: Long-Term Consequences of Obesity. American Sociological Review 68:70729.

Goyal NK, Fiks AG, Lorch SA. 2011. Association of late-preterm birth with asthma in young children: practice-based study. Pediatrics 128: 830-38.

Guo, G., \& Zhao, H. 2000. Multilevel modeling for binary data. Annual Review of Sociology 26: 441-462.

Grow, H. M. G., Cook, A. J., Arterburn, D. E., Saelens, B. E., Drewnowski, A., \& Lozano, P. 2010. Child obesity associated with social disadvantage of children's neighborhoods. Social Science \& Medicine 71(3): 584-591.

Harding DJ. 2009. Collateral consequences of violence in disadvantaged neighborhoods. Social Forces 88(2):757-82.

Harding DJ, Gennetian L, Winship C, Sanbonmatsu L, Kling J. 2010. Unpacking neighborhood influences on education outcomes: setting the stage for future research. National Bureau of Economic Research Working Paper No. 16055.

Halfon N, Kandyce L, Slusser W. 2013. Associations between obesity and comorbid mental health, developmental, and physical health conditions in a nationally representative sample of US children aged 10 to 17. Academic Pediatrics 13(1):6-13.

Houston, Texas City Website. 2017. http://www.houstontx.gov/planning/Demographics/ Accessed October 19, 2017. 
Jencks, C., \& Mayer, S. E. 1990.The social consequences of growing up in a poor neighborhood. In L. E. Lynn, \& M. G. H. McGeary (Eds.), Inner city poverty in the United States (pp. 111e186). Washington, DC: National Academy.

Jeon, L. Buettner, C.K., and E. Hur. 2014. Family and neighborhood disadvantage, home environment, and children's school readiness. Journal of Family Psychology 28: 718-727

Kimbro, Rachel Tolbert and Justin T. Denney. 2013. Neighborhood Context and Racial/Ethnic Differences in Young Children's Obesity: Structural Barriers to Interventions. Social Science \& Medicine 95:97-105.

http://dx.doi.org/10.1016/j.socscimed.2012.09.032

Kling JR, Liebman JB, Katz LF. 2005. Experimental analysis of neighborhood effects. NBER Working Paper: 11577.

Kreider, Amanda R., French, Benjamin, Aysola, Jaya, Saloner, Brendan et al. 2016. "Quality of Health Insurance Coverage and Access for Children in Low-Income Families." JAMA Pediatrics 170(1): 44-51.

Kristal RB, Blank AE, Wylie-Rosett J, Selwyn PA. 2015. Factors associated with daily consumption of sugar-sweetened beverages among adult patients at four federally qualified health centers, Bronx, New York, 2013. Preventing Chronic Disease 12:E02.

Lazarsfeld, Paul F. and Neil W. Henry. 1968. Latent Structure Analysis. Houghton Mifflin: Rancho Cucamonga: CA.

Leinberger, Christopher B. 2013. The WalkUP Wake-Up Call: Atlanta. Washington, DC: The George Washington University School of Business.

Leventhal, Tama and Jeanne Brooks-Gunn. 2000. The Neighborhoods They Live in: The Effects of Neighborhood Residence on Child and Adolescent Outcomes. Psychological Bulletin 126(2): 309-337.

Lewis, Valerie A., Emerson, Michael O., and Stephen L. Klineberg. 2011. Who We'll Live With: Neighborhood Racial Composition Preferences of Whites, Blacks and Latinos. Social Forces 89(4): 1385-1407 doi:10.1093/sf/89.4.1385.

Lobstein, Tim, Jackson-Leach, Rachel, Moodie, Marjory L., Hall, Kevin D., Gortmaker, Steven L., Swinburn, Boyd A., James, W Phillip T., Wang, Woufa, and Kim McPherson. (2015). Child and adolescent obesity: Part of a bigger picture. The Lancet (14): 1-11. http://dx.doi.org/10.1016/S0140-6736(14)61746-3. 
Ludwig, Jens, Sanbonmatsu, Lisa, Gennetian, Lisa, Adam, Emma, Duncan, Greg J., Katz, Lawrence F., Kessler, Ronald C., Kling, Jeffrey R., Lindau, Stacy Tessler, Whitaker, Robert C., and Thomas W. McDade. 2011. Neighborhoods, Obesity, and Diabetes - A Randomized Social Experiment. New England Journal of Medicine 365:1509-1519 DOI: 10.1056/NEJMsa1103216.

Manski, Charles F. Identification of Endogenous Social Effects: The Reflection Problem. The Review of Economic Studies 60(3): 531-542.

Massey, Douglas S., Andrew B. Gross, and Kumiko Shibuya. 1994. Migration, Segregation, and the Geographic Concentration of Poverty. American Sociological Review 59:425-45.

McCulloch, C. E., \& Searle, S. R. 2001. Generalized, Linear, and Mixed models. New York: Wiley.

Meyers, Jason L. and S. Natasha Beretvas. 2006. The Impact of Inappropriate Modeling of Cross-Classified Data Structures. Multivariate Behavioral Research 41(4): 473-497. doi: 10.1207/s15327906mbr4104_3

Muttarak, Raya. 2018. Normalization of plus size and the danger of the unseen overweight and obesity in England. Obesity 26: 1125-1129. https://doi.org/10.1002/oby.22204

Oberski, D.L. 2016. Beyond the number of classes: separating substantive from nonsubstantive dependence in latent class analysis. Advances in Data Analysis \& Classification 10: 171-182.

Pampel, Fred C., and Richard. G. Rogers. 2004. Socioeconomic Status, Smoking, and Health: A Test of Competing Theories of Cumulative Advantage. Journal of Health and Social Behavior 45: 306-21.

Pickett, K.E., \& Pearl, M. 2001. Multilevel analyses of neighborhood socioeconomic context and health outcomes: A critical review. Journal of Epidemiology and Community Health 55:111-122.

Powell AD, Kahn AS.1995 Racial differences in women's desires to be thin. International Journal of Eating Disorders 17:191-195.

Rabe-Hesketh, Sophia and Anders Skrondal. 2008. Multilevel and Longitudinal Modeling Using Stata, Second Edition. Stata Press: College Station, TX.

Raudenbush, S. W. and Bryk, A. S. 2002. Hierarchical linear models. Thousand Oaks, CA: Sage Publications. 
Roberto CA, Swinburn B, Hawkes C, Huang TTK, Costa SA, Ashe M, et al. 2015. Patchy Progress on Obesity Prevention: Emerging Examples, Entrenched Barriers, and New Thinking. Lancet 385: 2400-2409.

Robert Wood Johnson Foundation (RWJF) and Trust for America's Health. The State of Obesity 2017. Washington, D.C.: 2017.

Rosenbaum S. 2002. Medicaid. New England Journal of Medicine 346:635-640. doi: 10.1056/NEJM200202213460825.

Rossen, Lauren M. 2014. Neighbourhood economic deprivation explains racial/ethnic disparities in overweight and obesity among children and adolescents in the USA. Journal of Epidemiology \& Community Health 68:123-129 doi:10.1136/jech-2012202245.

Saelens BE, Sallis JF, Frank LD, Couch SC, Zhou C, Colburn T, Cain KL, Chapman J, Glanz K. 2012. Obesogenic neighborhood environments, child and parent obesity: the Neighborhood Impact on Kids study. American Journal of Preventative Medicine 42(5):57-64. doi: 10.1016/j.amepre.2012.02.008.

Sampson RJ. 2012. Great American City: Chicago and the Enduring Neighborhood Effect. Chicago: Univ. Chicago Press.

Sampson RJ, Morenoff JD, Gannon-Rowley T. 2002. Assessing "neighborhood effects": social processes and new directions in research. Annual Review of Sociology 28:44378.

Sampson RJ, Raudenbush SW. 1999. Systematic social observation of public spaces: a new look at disorder in urban neighborhoods. American Journal of Sociology 105(3):603-51.

SampsonRJ, Raudenbush SW,Earls F. 1997. Neighborhoods and violent crime: a multilevel study of collective efficacy. Science 277:918-24.

Sampson RJ, Sharkey P. 2008. Neighborhood selection and the social reproduction of concentrated racial inequality. Demographics 45:1-29.

Sampson RJ, Sharkey P, Raudenbush S. 2008. Durable effects of concentrated disadvantage on verbal ability among African-American children. Proceedings of the National Academies of Science USA 105:845-52.

Sharkey P. 2006. Navigating dangerous streets: the sources and consequences of street efficacy. American Sociological Review 71:826-46

Sharkey P. 2008. The intergenerational transmission of context. American Journal of Sociology 113:931-69. 
Sharkey P. 2010. The acute effect of local homicides on children's cognitive performance. Proceedings of the National Academy of Science USA 107:11733-38

Sharkey P. 2013. Stuck in Place: Urban Neighborhoods and the End of Progress Toward Racial Equality. Chicago: Univ. Chicago Press.

Sharkey P, Elwert F. 2011. The legacy of disadvantage: multigenerational neighborhood effects on cognitive ability. American Journal of Sociology 116:1934-81.

Sharkey, P. 2013. Stuck in place: Urban neighborhoods and the end of progress toward racial equality. Chicago, IL: University of Chicago Press.

Sharkey P, Schwartz AE, Ellen IG, Lacoe J. 2013. High stakes in the classroom, high stakes on the street: the effects of community violence on students' standardized test performance. Working Paper: 03-13, Institute of Education and Social Policy, New York University.

Sharkey, Patrick and Jacob W. Faber. 2014. Where, When, Why, and For Whom Do Residential Contexts Matter? Moving Away from the Dichotomous Understanding of Neighborhood Effects. Annual Review of Sociology 40: 559-579; DOI: 10.1146/annurevsoc-071913-043350

Shonkoff, Jack P. and Deborah A. Phillips (Eds). 2000. From Neurons to Neighborhoods: The Science of Early Childhood Development. Washington, D.C., National Academy Press.

Singh, G. K., Siahpush, M., \& Kogan, M. D. 2010. Neighborhood socioeconomic conditions, built environments, and childhood obesity. Health Affairs 29: 503-512.

Singh, G.K. and R.M. Ghandour. 2012. Impact of neighborhood social conditions and household socioeconomic status on behavioral problems among US children. Maternal \& Child Health Journal16:158-169

Sokal-Gutierrez, Karen. 2017. "Will overweight children be overweight adults? New England Journal of Medicine Resident 360.

Swinburn BA, Sacks G, Hall KD, et al. 2011.The global obesity pandemic: shaped by global drivers and local environments. Lancet 378: 804-815.

Tabarrok, Alex, Healton, Paul, and Eric Helland. 2010. The measure of vice and sin: A review of the uses, limitations, and implication of crime data. In: Handbook on the Economics of Crime. Northhampton, MA: Edward Elgar Publishing. 
Tienda, Marta. 1991. "Poor People and Poor Places: Deciphering Neighborhood Effects on Poverty Outcomes." Pp. 244-62 in Macro-Micro Linkages in Sociology, edited by J. Huber. Newbury Park, CA: Sage.

Townshend, T., \& Lake, A. A. 2009. Obesogenic urban form: theory, policy and practice. Health \& Place 15(4): 909-916.

Umberson, Debra, Crosnoe, Robert, and Corinne Reczek. 2010. Social relationships and health behavior across the life course. Annual Review of Sociology 36:139-57.

Vermunt, J.K., and Magidson, J. (2002). Latent class cluster analysis. J.A. Hagenaars and A.L. McCutcheon (eds.), Applied Latent Class Analysis, 89-106. Cambridge University Press.

Wang, Y., \& Beydoun, M. A. 2007. The obesity epidemic in the United States-gender, age, socioeconomic, racial/ethnic, and geographic characteristics: a systematic review and meta-regression analysis. Epidemiologic reviews 29(1): 6-28.

Wang YC, McPherson K, Marsh T, Gortmaker SL, Brown M. 2011. Health and economic burden of the projected obesity trends in the USA and the UK. Lancet 378 : 815-25.

Wang et al. 2011. Trends and racial / ethnic disparities in severe obesity among US children and adolescents 1976-2006. International Journal of Pediatric Obesity 6(1): 1220.

Wang, Youfa and Hsin-Jen Chen. 2012. Use of percentiles and Z-scores in Anthropometry. In Handbook of anthropometry: Physical measures of human form in health and disease, V.R. Preedy (ed.) Springer Science Business Media: New York.

White, Michael J. 1987. American Neighborhoods and Residential Differentiation. New York: Russell Sage Foundation. 
Table 1. Descriptive Neighborhood-level Statistics by Neighborhood Types Created through LPA

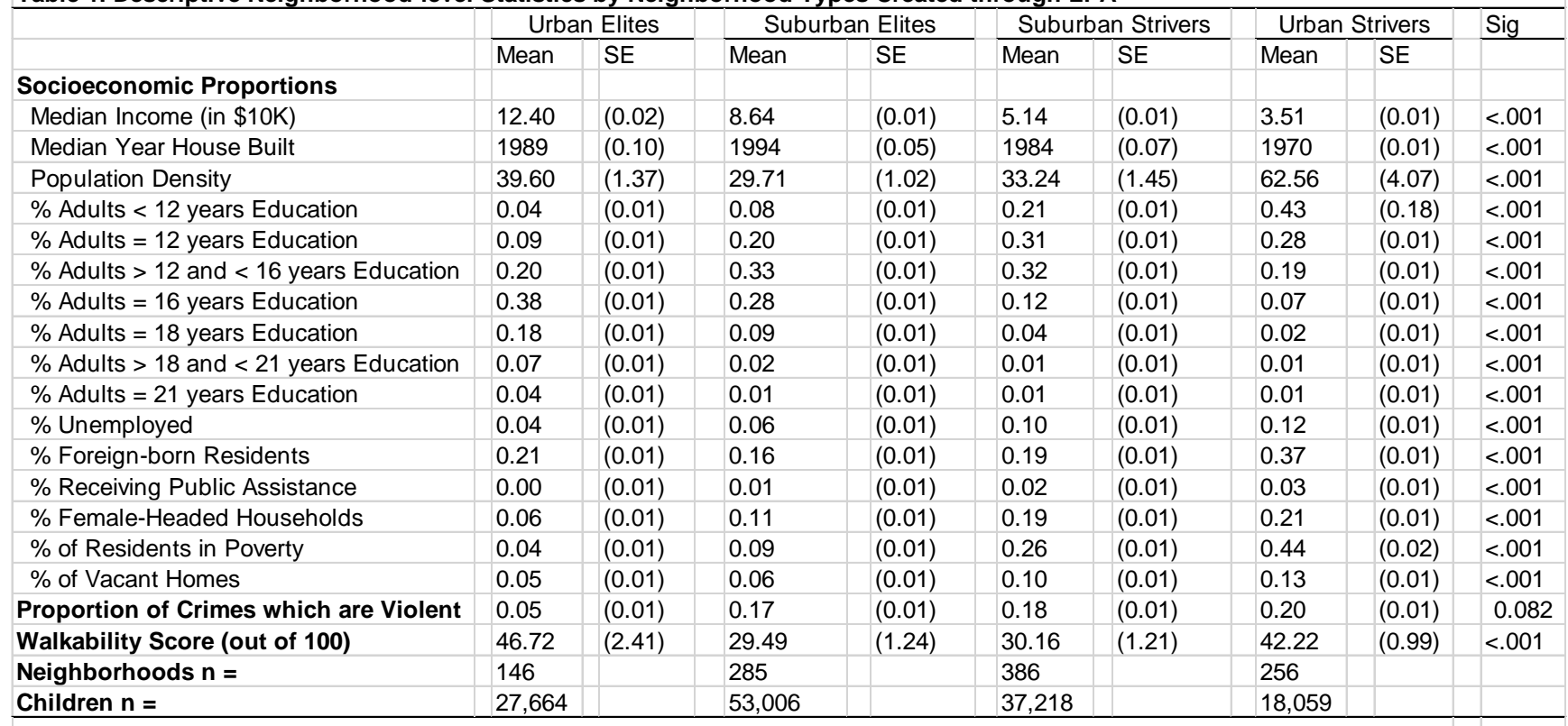

Source: Data are from the Authors' Compilation of Electronic Medical Records, the Census, American Communtiy Survey (ACS), Houston Crime Data, and Walkscore.com Note: Significance is evaluated using One-Way MANOVA with the neighborhood variables as the dependent variables and LPA neighborhood type as the independent variable. 
Table 2. Child and Family Descriptive Statistics Overall and by Neighborhood Types Created through LPA

\begin{tabular}{|c|c|c|c|c|c|c|c|c|c|c|c|c|c|}
\hline & \multicolumn{2}{|c|}{ Overall } & \multicolumn{2}{|c|}{ Urban Elites } & \multicolumn{2}{|c|}{ Suburban Elites } & \multirow[t]{2}{*}{ Sig } & \multicolumn{2}{|c|}{ Suburban Strivers } & \multirow[t]{2}{*}{ Sig } & \multicolumn{2}{|c|}{ Urban Strivers } & \multirow[t]{2}{*}{ Sig } \\
\hline & Mean & SE & Mean & SE & Mean & SE & & Mean & SE & & Mean & SE & \\
\hline \multicolumn{14}{|l|}{ Health Outcome } \\
\hline Obesity & 0.08 & $(0.01)$ & 0.04 & $(0.01)$ & 0.06 & $(0.01)$ & $<.001$ & 0.10 & $(0.01)$ & $<.001$ & 0.13 & $(0.01)$ & $<.001$ \\
\hline \multicolumn{14}{|c|}{ Individual Characteristics } \\
\hline Age at Visit & 5.70 & $(0.01)$ & 5.78 & $(0.01)$ & 5.74 & $(0.01)$ & 0.09 & 5.66 & $(0.01)$ & $<.001$ & 5.55 & $(0.01)$ & $<.001$ \\
\hline \multicolumn{14}{|l|}{ Gender } \\
\hline Male & 0.51 & $(0.01)$ & 0.51 & $(0.01)$ & 0.52 & $(0.01)$ & 0.29 & 0.51 & $(0.01)$ & 0.62 & 0.52 & $(0.01)$ & 0.39 \\
\hline \multicolumn{14}{|l|}{ Racel Ethnicity } \\
\hline Non-Hispanic White & 0.49 & $(0.01)$ & 0.68 & $(0.01)$ & 0.62 & $(0.01)$ & 0.07 & 0.34 & $(0.01)$ & $<.001$ & 0.11 & $(0.01)$ & $<.001$ \\
\hline Non-Hispanic Black & 0.16 & $(0.01)$ & 0.05 & $(0.01)$ & 0.12 & $(0.01)$ & $<.001$ & 0.29 & (0.01) & $<.001$ & 0.20 & $(0.01)$ & $<.001$ \\
\hline Hispanic & 0.28 & $(0.01)$ & 0.11 & $(0.01)$ & 0.18 & $(0.01)$ & $<.001$ & 0.35 & $(0.01)$ & $<.001$ & 0.67 & $(0.01)$ & $<.001$ \\
\hline Asian/ Other Race & 0.07 & $(0.01)$ & 0.15 & $(0.01)$ & 0.07 & $(0.01)$ & $<.001$ & 0.03 & (0.01) & $<.001$ & 0.02 & $(0.01)$ & 0.01 \\
\hline \multicolumn{14}{|l|}{ Health Insurance } \\
\hline Private Provider & 0.71 & $(0.01)$ & 0.94 & $(0.01)$ & 0.85 & $(0.01)$ & $<.001$ & 0.56 & $(0.01)$ & $<.001$ & 0.30 & $(0.01)$ & $<.001$ \\
\hline Public Provider & 0.29 & $(0.01)$ & 0.06 & $(0.01)$ & 0.15 & $(0.01)$ & $<.001$ & 0.44 & $(0.01)$ & $<.001$ & 0.70 & $(0.01)$ & $<.001$ \\
\hline Neighborhoods $\mathbf{n}=$ & 1,076 & & 146 & & 285 & & & 386 & & & 256 & & \\
\hline Children $\mathbf{n}=$ & 135,947 & & 27,664 & & 53,006 & & & 37,218 & & & 18,059 & & \\
\hline
\end{tabular}




\begin{tabular}{|c|c|c|c|c|c|c|c|c|c|c|c|c|c|c|c|c|}
\hline & \multicolumn{3}{|c|}{ Model 1} & \multicolumn{3}{|c|}{ Model 2} & \multicolumn{3}{|c|}{ Model 3} & \multicolumn{3}{|c|}{$\begin{array}{l}\text { Stratified Model 4: } \\
\text { Private Only }\end{array}$} & \multicolumn{3}{|c|}{$\begin{array}{l}\text { Stratified Model 5: } \\
\text { Public Only }\end{array}$} & \multirow{2}{*}{$\begin{array}{c}\begin{array}{c}\text { Private versus } \\
\text { Public }\end{array} \\
Z\end{array}$} \\
\hline & Coeff. & SE & OR & Coeff. & SE & OR & Coeff. & SE & OR & Coeff. & SE & OR & Coeff. & SE & OR & \\
\hline Intercept & $-2.81^{\star \star \star}$ & 0.11 & $0.06^{\star \star *}$ & $-3.52^{\star \star \star}$ & 0.11 & $0.03^{\star \star \star}$ & $-3.64^{\star \star \star}$ & 0.11 & $0.03^{\star \star \star}$ & $-3.72^{\star \star \star}$ & 0.13 & $0.02^{\star \star \star}$ & $-2.61^{\star \star \star}$ & 0.17 & $0.07^{\star \star \star}$ & \\
\hline \multicolumn{17}{|l|}{ Demographics } \\
\hline Age at visit & $0.20^{\star \star \star}$ & 0.00 & $1.22^{\star \star *}$ & $0.20^{\star \star \star}$ & 0.00 & $1.22^{\star \star \star}$ & $0.20^{\star \star \star}$ & 0.00 & $1.22^{\star \star *}$ & $0.20^{\star \star \star}$ & 0.00 & $1.22^{\star \star \star}$ & $0.20^{\star \star *}$ & 0.01 & $1.23^{\star \star *}$ & 0.00 \\
\hline \multicolumn{17}{|l|}{ Gender (female, ref) } \\
\hline Male & -0.03 & 0.02 & 0.97 & -0.03 & 0.02 & 0.97 & -0.03 & 0.02 & 0.97 & -0.02 & 0.03 & 0.98 & -0.04 & 0.03 & 0.96 & 0.50 \\
\hline \multicolumn{17}{|c|}{ Racel ethnicity (non-Hispanic white, ref) } \\
\hline Non-Hispanic Black & $0.46^{\star \star \star}$ & 0.03 & $1.59^{\star \star \star}$ & $0.37^{\star \star \star}$ & 0.03 & $1.45^{\star \star \star}$ & $0.36^{\star \star \star}$ & 0.03 & $1.43^{\star \star \star}$ & $0.52^{\star \star \star}$ & 0.04 & $1.69^{\star \star \star}$ & 0.07 & 0.06 & 1.07 & $6.45^{\star \star \star}$ \\
\hline Hispanic & $0.78^{\star \star \star}$ & 0.02 & $2.17^{\star \star \star}$ & $0.68^{\star \star \star}$ & 0.03 & $1.97^{\star \star \star}$ & $0.66^{\star \star \star}$ & 0.03 & $1.93^{\star \star \star}$ & $0.68^{\star \star \star}$ & 0.03 & $1.97^{\star \star \star}$ & $0.50^{\star \star \star}$ & 0.05 & $1.65^{\star \star \star}$ & $3.60^{\star \star \star}$ \\
\hline Asian/ Other Race & $-0.24^{\star \star \star}$ & 0.06 & $0.79^{\star \star \star}$ & $-0.19^{\star}$ & 0.06 & $0.833^{*}$ & $-0.19^{*}$ & 0.06 & $0.83^{*}$ & $-0.14^{*}$ & 0.07 & $0.87^{\star}$ & $-0.47^{\star}$ & 0.15 & $0.63^{*}$ & 0.17 \\
\hline Child is publically insured & $0.33^{\star \star \star}$ & 0.04 & $1.39^{\star \star \star}$ & $0.21^{\star \star \star}$ & 0.03 & $1.23^{\star \star \star}$ & $0.80^{\star \star \star}$ & 0.11 & $2.22^{\star \star \star}$ & & & & & & & \\
\hline \multicolumn{17}{|l|}{ Neighborhoods (Urban Elites, ref) ${ }^{a}$} \\
\hline Suburban Elites & & & & $0.51^{\star \star \star}$ & 0.05 & $1.67^{\star \star \star}$ & $0.54^{\star \star \star}$ & 0.05 & $1.72^{\star \star \star}$ & $0.54^{\star \star \star}$ & 0.05 & $1.71^{\star \star \star}$ & 0.16 & 0.10 & 1.17 & $30.40^{\star \star \star}$ \\
\hline Suburban Strivers & & & & $0.84^{\star \star \star}$ & 0.05 & $2.31^{\star \star \star}$ & $1.01^{\star \star \star}$ & 0.05 & $2.75^{\star \star \star}$ & $0.99^{\star \star \star}$ & 0.06 & $2.70^{\star \star \star}$ & $0.28^{*}$ & 0.10 & $1.32^{*}$ & $52.20^{\star \star \star}$ \\
\hline Urban Strivers & & & & $0.96^{\star \star *}$ & 0.05 & $2.61^{\star \star *}$ & $1.10^{\star \star \star}$ & 0.07 & $3.03^{\star \star *}$ & $1.09^{\star \star \star}$ & 0.06 & $2.97^{\star \star \star}$ & $0.45^{\star \star *}$ & 0.09 & $1.57^{\star \star \star}$ & $5.92^{\star \star \star}$ \\
\hline Log of Population Density & -0.03 & 0.01 & 0.97 & -0.01 & 0.01 & 0.99 & 0.00 & 0.01 & 1.00 & 0.01 & 0.02 & 1.01 & -0.01 & 0.02 & 0.99 & 0.31 \\
\hline \multicolumn{17}{|l|}{ Interaction Effects (Urban Elites, ref) } \\
\hline Suburban Elites*public insurance & & & & & & & $-0.37^{\star \star}$ & 0.11 & $0.69^{\star \star}$ & & & & & & & \\
\hline Suburban Strivers*public insurance & & & & & & & $-0.75^{\star \star \star}$ & 0.11 & $0.47^{\star \star \star}$ & & & & & & & \\
\hline Urban Striverspublic insurance & & & & & & & $-0.67^{\star \star \star}$ & 0.11 & $0.51^{\star \star \star}$ & & & & & & & \\
\hline \multicolumn{17}{|l|}{ Random Effects } \\
\hline Intercept & 0.43 & 0.13 & & 0.34 & 0.24 & & 0.32 & 0.25 & & $0.21^{\star \star \star}$ & 0.02 & & 0.12 & 0.05 & & \\
\hline Insurance & $0.34^{\star \star \star}$ & 0.02 & & $0.21^{\star \star *}$ & 0.02 & & $0.19^{\star \star \star}$ & 0.02 & & & & & & & & \\
\hline
\end{tabular}

${ }^{\star} p<.05,{ }^{\star \star} p<.01,{ }^{\star \star \star} \mathrm{p}<.001$

${ }^{a}$ All tests for differences between Private and Public Insurance holders in Models 4 and 5 evaluated using Clogg's Test at the $99.9 \%$ confidence level of a two-tailed unit normal distribution. 
Figure 1:

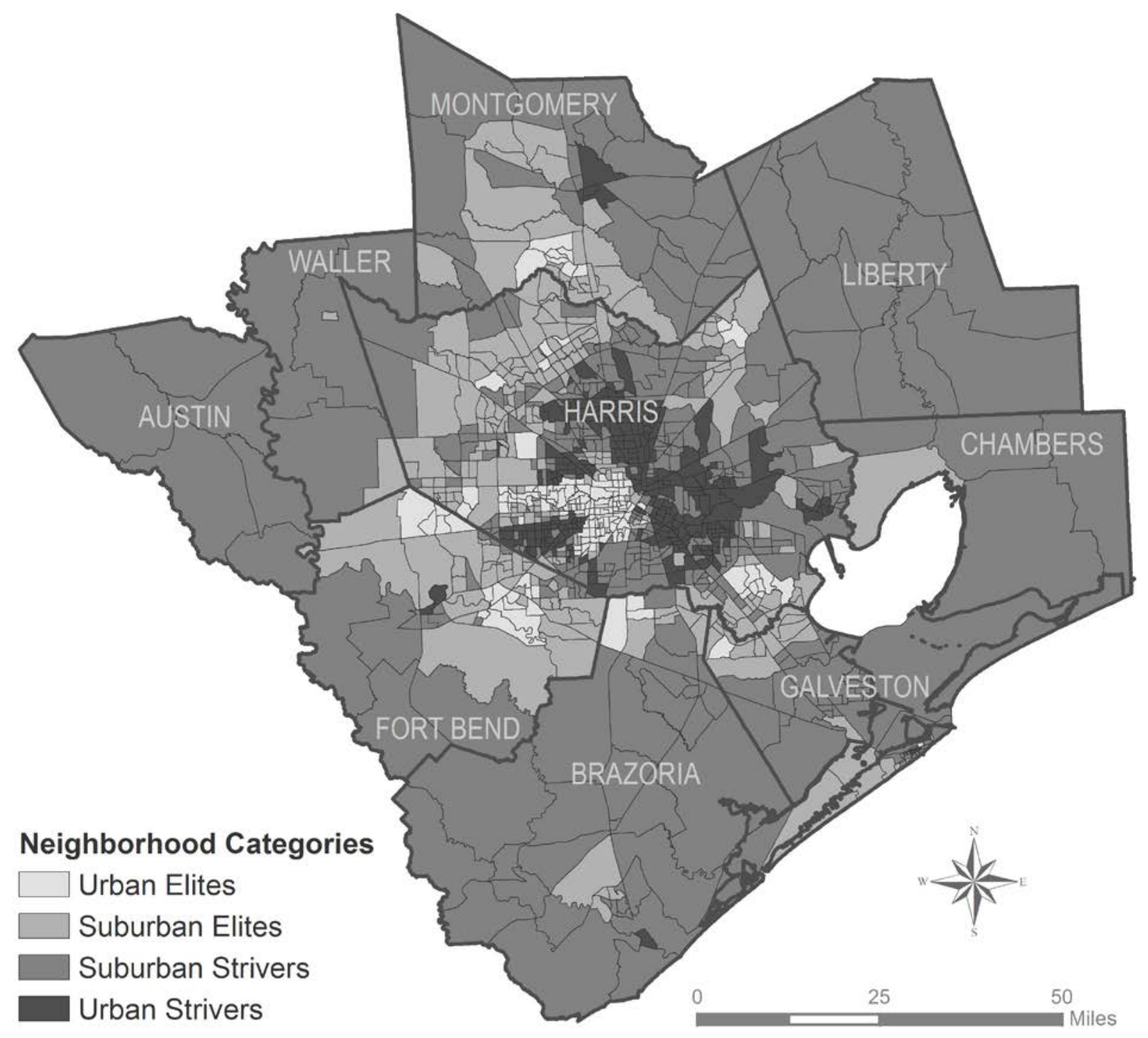


Figure 2. Distribution of Children across Neighborhood Contexts by Insurance Type

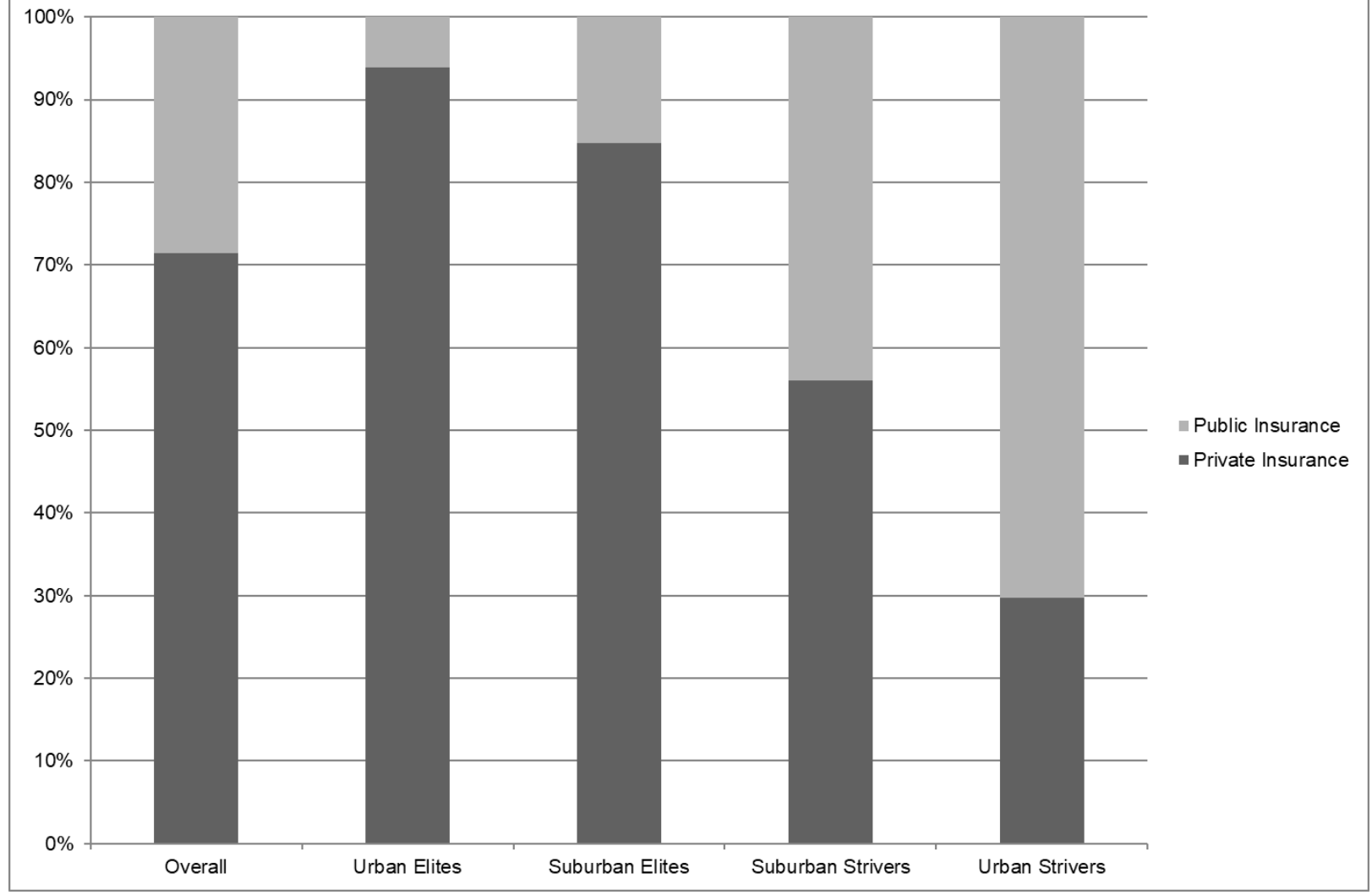




\section{Figure 3. Fully Adjusted Predicted Probability of Obesity, by Insurance Type and Neighborhood Type}

0.16

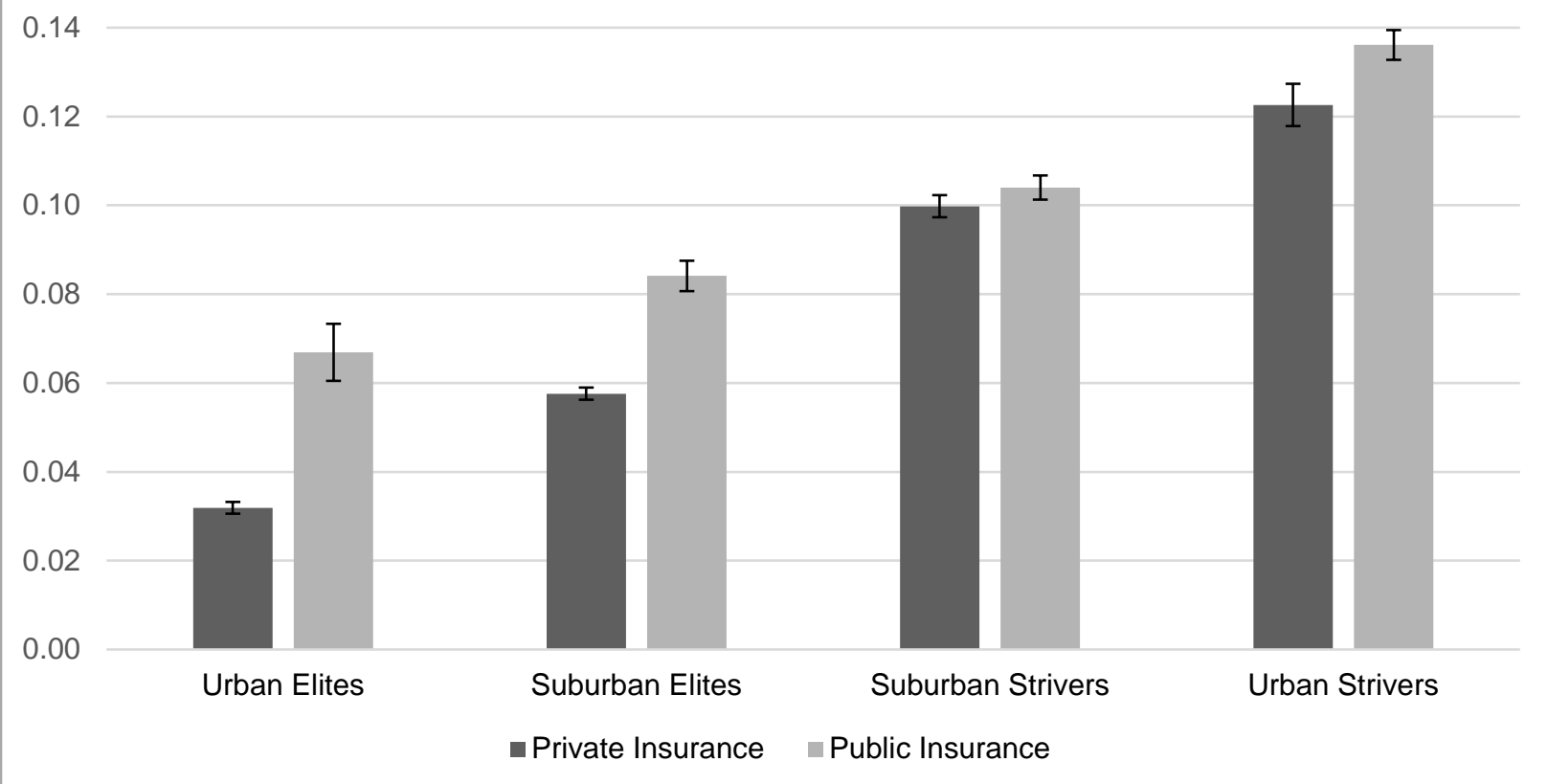




\section{Online Resource 1. Model Fit Information for LPAs}

with 1 - 5 Latent Profiles

\begin{tabular}{|c|c|c|c|c|l|}
\hline Classes & AlC & BIC & a-BIC & LL & Entropy \\
\hline 1 & -8868.21 & -8885.13 & -8834.20 & 5971.79 & 1.00 \\
\hline 2 & -8774.39 & -8737.25 & -8743.46 & 4886.07 & 0.24 \\
\hline 3 & -8512.48 & -8641.33 & -8582.12 & 4606.16 & 0.28 \\
\hline 4 & -8349.99 & -8457.49 & -8407.09 & 4472.99 & $\mathbf{0 . 3 1}$ \\
\hline 5 & -8451.24 & -8513.54 & -8467.2 & 4503.78 & 0.32 \\
\hline
\end{tabular}

Source: Data are from the Authors' Compilation of Electronic Medical Records, the

Census, American Communtiy Survey (ACS), Houston Crime Data, and Walkscore.com 